\title{
SIMULTANEOUS OPERATIONS DURING UMBILICAL AND PARAUMBILICAL HERNIA REPAIR: POSSIBLE OR NECESSARY?
}

DOI:10.36740/WLek202102108

\author{
Valeriy V. Boiko', Kyrylo Yu. Parkhomenko ${ }^{2}$, Kostyantyn L. Gaft', Oleksandr E. Feskov ${ }^{3}$ \\ 'STATE INSTITUTION «INSTITUTE OF GENERAL AND EMERGENCY SURGERY NAMED AFTER V.T. ZAITSEV OF THE NATIONAL ACADEMY OF MEDICAL \\ SCIENCES OF UKRAINE», KHARKIV, UKRAINE \\ 2KHARKIV NATIONAL MEDICAL UNIVERSITY, KHARKIV, UKRAINE \\ ${ }^{3}$ KHARKIV MEDICAL ACADEMY OF POSTGRADUATE EDUCATION, KHARKIV, UKRAINE
}

\begin{abstract}
The aim of the study was to determine the possibility and effectiveness of simultaneous surgical interventions in umbilical and paraumbilical hernia repair. Material and methods: 148 case histories were analyzed concerning patients who were routinely admitted to the surgical department of the Kharkiv Regional Council's Municipal Non-Profit Enterprise «Regional Clinical Hospital» between 2017 and 2019, and who underwent umbilical and paraumbilical hernia repair simultaneously with operations related to some other surgical pathology (group 1,n=67) or in separate interventions (group $2, n=81$ ). All patients were routinely operated after a set of mandatory and additional general clinical, laboratory and instrumental research conducted in accordance with the existing guidelines. The structure and results of surgical interventions related to the underlying disease and simultaneous operations were studied.

Results: Simultaneous operations were performed for comorbid cholecystolithiasis, diaphragmatic esophageal hernia with gastroesophageal reflux, inguinal hernia, white line hernia, benign diseases of the uterus and uterine appendages et al. The frequency of complications and recurrences of hernia in patients with simultaneous and isolated of umbilical hernia repair did not differ significantly. The outcome of the operation mostly depended on the method of operation (postoperative complications were most often observed in open sutures repair and were absent in laparoscopic hernia repair). Additional risk factors were weight gain and diabetes.

Conclusions: Summarizing the data obtained, it can be concluded that application of modern endovideoscopic techniques in surgery makes simultaneous surgical interventions not only possible but also necessary in the presence of concomitant abdominal pathology that requires surgical treatment.
\end{abstract}

KEY WORDS: umbilical hernias, paraumbilical hernias, simultaneous operations, postoperative complications, hernia recurrences

\section{INTRODUCTION}

In most countries of the world, as far as the structure of routine and emergency abdominal interventions is concerned, hernia repair occupies one of the leading places. According to a population-based study, the anterior abdominal wall hernias in patients older than 10 years of age are found in $20.9 \%$ of the population, and most often it is umbilical hernia, with prevalence of $10.2 \%[1,2]$. Based upon the results of their ultrasound studies, M.A. Bedewi et al. established that prevalence of umbilical and paraumbilical hernias can be as high as 25\% [3]. Among the patients who underwent surgery the incidence rate of such hernias is $13.3 \%$ [4].

The optimal method of treatment of patients with umbilical and paraumbilical hernias is considered to be the one that involves open access mesh endoprosthesis hernia repair with peritoneal mesh placement. Laparoscopic access may be useful in cases of a large hernia defect and an increased risk of wound complications [5]. However, in recent years there have been numerous reports concerning simultaneous, or concurrent, surgical treatment of two or more abdominal diseases that require surgical intervention [6-9].

In terms of the impact of access and plastics method on immediate and long-term results of hernioplasty, the choice of hernia repair method in simultaneous operations remains pertinent and requires further research.

\section{THE AIM}

The aim of the study was to determine the possibility and effectiveness of simultaneous surgical interventions in umbilical and paraumbilical hernia repair.

\section{MATERIAL AND METHODS}

148 case histories were analyzed concerning patients who were routinely admitted to the surgical department of the Kharkiv Regional Council's Municipal Non-Profit Enterprise «Regional Clinical Hospital» between 2017 and 2019, and who underwent umbilical and paraumbilical hernia repair simultaneously with operations related to some other surgical pathology (group 1, $\mathrm{n}=67$ ) or in separate interventions (group 2, $\mathrm{n}=81$ ). 
Table 1. Concomitant pathology in patients of group 1 and 2.

\begin{tabular}{|c|c|c|c|}
\hline Descriptor & Group 1 & Group 2 & $\mathbf{p}$ \\
\hline Gender, F/M & $40(60 \%) / 27(40 \%)$ & $36(44 \%) / 45(55 \%)$ & $>0.05^{1}$ \\
\hline Average age, years & $51.3 \pm 13.2$ & $51.3 \pm 16.1$ & $>0.05^{2}$ \\
\hline $\begin{array}{l}\text { Type of hernia: } \\
\text { - umbilical } \\
\text { - paraumbilical }\end{array}$ & $\begin{array}{c}65(97 \%) \\
2(3 \%)\end{array}$ & $\begin{array}{c}73(90 \%) \\
8(9.9 \%)\end{array}$ & $>0.05^{2}$ \\
\hline $\begin{array}{l}\text { Size of hernia: } \\
\quad-<2 \mathrm{~cm} \\
-2-4 \mathrm{~cm} \\
>4 \mathrm{~cm}\end{array}$ & $\begin{array}{l}13(19 \%) \\
41(61 \%) \\
13(19 \%)\end{array}$ & $\begin{array}{l}14(17 \%) \\
53(65 \%) \\
14(17 \%)\end{array}$ & $>0.05^{2}$ \\
\hline \multicolumn{4}{|l|}{ Concomitant pathology: } \\
\hline Diabetes mellitus, n (\%) & $4(6 \%)$ & $4(5 \%)$ & $>0.05^{1}$ \\
\hline $\begin{array}{l}\text { Excess weight, } \mathrm{n}(\%): \\
\text { Body mass index } 25-30 \mathrm{~kg} / \mathrm{m}^{2} \\
\text { Body mass index }>30 \mathrm{~kg} / \mathrm{m}^{2}\end{array}$ & $\begin{array}{c}22(33 \%) \\
7(10 \%) \\
\end{array}$ & $\begin{array}{c}24(30 \%) \\
4(5 \%) \\
\end{array}$ & $>0.05^{1}$ \\
\hline Arterial hypertension, $\mathrm{n}(\%)$ & $29(43 \%)$ & $27(33 \%)$ & $>0.05^{1}$ \\
\hline Coronary heart disease, n (\%) & $7(10 \%)$ & $11(14 \%)$ & $>0,05^{1}$ \\
\hline Chronic cardiac failure, n (\%) & $12(18 \%)$ & $12(15 \%)$ & $>0.05^{1}$ \\
\hline Chronic obstructive pulmonary disease, n (\%) & $2(3 \%)$ & $4(5 \%)$ & $>0.05^{1}$ \\
\hline
\end{tabular}

Note: ${ }^{1}$ reliability in regard to $\times 2$ criterion; ${ }^{2}$ reliability in regard to t-test

Table 2. Methods of umbilical hernia repair surgery.

\begin{tabular}{ccc}
\hline Descriptor & Group 1 & Group 2 \\
\hline Laparoscopic alloplasty (IPOM technique) & $40(60 \%)$ & $16(20 \%)$ \\
\hline Hybrid alloplasty & $23(34 \%)$ & - \\
\hline Onlay technique & Open alloplasty: & $2(2.5 \%)$ \\
\hline Inlay technique & - & $8(10 \%)$ \\
\hline Sublay technique & $1(1.5 \%)$ & $37(46 \%)$ \\
\hline Mayo open autografting & $2(3.0 \%)$ & $18(22 \%)$ \\
\hline
\end{tabular}

Note: IPOM - intraperitoneal onlay mesh.

The patients in both groups were similar as far gender, age and frequency of comorbidities (Table 1). Various methods of hernia repair surgery were used for treatment of umbilical hernias (Table 2).

IPOM hernia repair and hybrid alloplasty predominated in patients who underwent simultaneous surgeries (group 1): in a number of cases open hernia repair techniques were used. In group 2 mesh endoprosthesis alloplasty was generally performed, and open Mayo hernia repair was performed quite often.

In addition to the above mentioned concomitant pathology, the patients of group I had other diseases, which were indications for simultaneous surgery (table 3 ).

All patients were routinely operated after a set of mandatory and additional general clinical, laboratory and instrumental research conducted in accordance with the existing guidelines. The structure and results of surgical interventions related to the underlying disease and simultaneous operations were studied.

The obtained results were processed using PSSP statistical software package and applying the frequency analysis method and making use of Fisher's Exact Test and $\chi^{2}$ criterion for comparison of qualitative characteristics, and the $\mathrm{t}$-test for comparison of quantitative characteristics. The difference between the groups was considered to be significant at $(\mathrm{p}<0.05)$. The results are given in the form of absolute count (\%) for qualitative characteristics and in the form of $\mathrm{M} \pm \mathrm{SD}$ (mean and standard deviation of the mean) for quantitative characteristics.

\section{RESULTS}

In the early postoperative period 21 (14.2\%) complications were detected; usually it was a seroma and hematoma in the postoperative wound, less frequently it was infiltrate inside the wound, which did not require additional interventions. In one case sutures had to be removed due to surface inflammation in a limited area. Recurrences were detected in $9(6.1 \%)$ patients. No impact of simultaneous surgery on the development of complications, duration of hospitalization and recurrence rate one year after surgery and 
Table 3. Comorbidities and simultaneous operations in regard to Group I patients

\begin{tabular}{cccc}
\hline Diagnosis & Operation & Number & \% \\
\hline Cholecystolithiasis & Laparoscopic cholecystectomy & 30 & 45 \\
\hline $\begin{array}{c}\text { Hernia of the esophageal orifice of the } \\
\text { diaphragm }\end{array}$ & Posterior cruroraphia, Nissen fundoplication & 6 & 9 \\
\hline Inguinal hernia & TAPP hernia repair & 4 & 1 \\
\hline Epigastric hernia & IPOM hernia repair & 1 & 12 \\
\hline Benign diseases of uterus & Uterectomy & 8 & 18 \\
\hline Adnexal diseases & Salpingectomy / ovariectomy, cystectomy & 3 & 12 \\
\hline Adiposity & Sleeve Gastrectomy & 1 & \\
\hline Benign skin tumors & Tumor removal & 1.5 \\
\hline Urachal cyst & Urachal cyst removal & 1.5 \\
\hline Chronic appendicitis & Laparoscopicappendectomy & 1.5 \\
\hline
\end{tabular}

Note: Transabdominal pre-peritoneal - TAPP; Transabdominal pre-peritoneal (TAPP).

Table 4. Actual results of operations.

\begin{tabular}{|c|c|c|c|}
\hline Descriptor & Group 1 & Group 2 & $\mathbf{p}$ \\
\hline Wound complications, n (\%): & $8(12 \%)$ & $13(16 \%)$ & \\
\hline - seroma & $4(6 \%)$ & $5(6 \%)$ & \\
\hline - hematoma & $3(4.5 \%)$ & $5(6 \%)$ & $>0.05^{1}$ \\
\hline - infiltrate & $1(1.5 \%)$ & $2(2.5 \%)$ & \\
\hline - inflammation & - & $1(1 \%)$ & \\
\hline Duration of hospitalization, days & $6.7 \pm 1.5$ & $6.5 \pm 2.0$ & $>0.05^{2}$ \\
\hline Recurrences, n (\%) & $3(4.5 \%)$ & $6(7 \%)$ & $>0.05^{1}$ \\
\hline
\end{tabular}

Note: ${ }^{1}$ reliability in regard to $\times 2$ criterion, ${ }^{2}$ reliability in regard to t-criterion;

Table 5. Incidence of complications and recurrences, depending on the hernia repair techniques

\begin{tabular}{ccc}
\hline Surgical technique & Complications & Hernia recurrence \\
\hline Mayo open hernioplasty, $\mathrm{n}=19$ & $5(26 \%)$ & $3(16 \%)$ \\
\hline Open alloplasty, $\mathrm{n}=50$ & $8(16 \%)$ & $4(8 \%)$ \\
\hline Laparoscopic alloplasty (IPOM technique), $\mathrm{n}=56$ & $3(5 \%)$ & - \\
\hline Hybrid alloplasty, $\mathrm{n}=5$ & $5(22 \%)$ & $2(9 \%)$ \\
\hline
\end{tabular}

Table 6. Incidence of complications and recurrences depending on the size of hernia and concomitant diseases, not related to abdominal cavity.

\begin{tabular}{ccc}
\hline Descriptor & Complication & Hernia recurrence \\
\hline Size of hernia: & & $1(4 \%)^{1}$ \\
$<2 \mathrm{~cm}, \mathrm{n}=27$ & $4(15 \%)^{1}$ & $4(4 \%)$ \\
$2-4 \mathrm{~cm}, \mathrm{n}=94$ & $12(13 \%)$ & $4(15 \%)$ \\
$>4 \mathrm{~cm}, \mathrm{n}=27$ & $5(18,5 \%)$ & $8(14 \%)^{2}$ \\
\hline Excess weight (Body mass index over $\left.25 \mathrm{~kg} / \mathrm{m}^{2}\right):$ & $12(21 \%)^{1}$ & $1(1 \%)$ \\
yes, $\mathrm{n}=57$ & $9(10 \%)$ & $4(44 \%)^{2}$ \\
no, $\mathrm{n}=91$ & $2(22 \%)^{1}$ & $5(4 \%)$ \\
\hline Diabetes mellitus: & $19(14 \%)$ & \\
\hline nos, $\mathrm{n}=139$ & & \\
\hline
\end{tabular}

Note: ${ }^{1} p>0.05$ in regard to $\times 2$ criterion, ${ }^{2} p<0.05$ in regard to $\times 2$ criterion.

later was detected one year after surgery and later. On the contrary, the incidence of complications and recurrences in group 1 demonstrates a tendency to reduction (table 4).

This tendency can be explained by the difference in the structure of hernioplasty techniques used for group 1 and group 2, which is demonstrated by the analysis of actual results, depending on umbilical and paraumbilical hernia repair techniques utilized (table 5 ).

The greatest number of complications was observed following open hernia repair, which was generally used for group 2 patients, and the smallest number of complications was reported after laparoscopic alloplasty, which 
was prevalent in patients who underwent simultaneous operations (group I).

Incidence of complications and recurrences depending on the presence of known risk factors was analyzed separately (table 6).

An unsubstantiated tendency to increase of the number of complications with the increase in hernia size, weight gain and in the presence of diabetes was identified. More pronounced relationships can be determined by analyzing the incidence of recurrences: the latter most certainly increased with the increase in weight and in the presence of diabetes mellitus.

\section{DISCUSSION}

Comparison of the incidences of complications after simultaneous and separate umbilical hernia repairs did not show significant differences $(12 \%$ and $16 \%$ respectively, with $\mathrm{p}>0.05)$. In both groups, the most common were seromas, which were found in $6 \%$ of cases in each group, and hematomas $-4.5 \%$ and $6 \%$ respectively ( $p>0.05)$. In several cases infiltrate or inflammation of the postoperative wound were observed. This is consistent with the results obtained by other researchers. Thus, Shankar et al. observed wound complications in $18 \%$ of cases, among which percentage seromas amounted to $6.3 \%[10]$. But in a study by M.W. Christoffersen et al. the incidence of seromas after IPOM hernia repair amounted to $58 \%$ (in regard to largeand medium-sized umbilical hernias) [11], while J.M. Shao et al. reported a much lower incidence of complications: surgical site infection $-2.7 \%$, hematomas $-1.1 \%$, seromas $-2.7 \%$ [12]. This scatter is likely due to additional factors that need to be considered when assessing the development of complications. It should be noted that there were no differences between the groups in terms of gender, age, frequency of concomitant non-surgical pathology and characteristics of hernia.

According to our findings, the method of surgery was the most influential factor in the development of complications. Thus, after using conventional open suturing technique with tissue materials (Mayo) the incidence of complications amounted to $26 \%$; the lowest incidence was observed after laparoscopic alloplasty - $5 \%$. However, quite high incidence of complications was also observed after open mesh alloplasty (16\%) and hybrid alloplasty (22\%), and most of complications were represented by seromas and hematomas. More frequent formation of seromas and hematomas following the use of such hernia repair techniques can be explained by an enlarged wound, the need for tissue separation manipulations and the presence of a mesh endoprosthesis.

Similar tendencies were established when comparing the incidence of recurrences. In the group of patients who underwent simultaneous surgical operations, during observation lasting from 1 to 2 years they were observed in $4.5 \%$ of the cases, and in the group of patients who underwent separate hernia repair - in $7 \%$ of the cases ( $p>0.05)$. This is also consistent with the results obtained by other researchers. Thus, K. Donovan et al. found that the umbilical hernia recurrence rate after open mesh or suture hernia repair amounted to $3.3 \%$ [13]. According to M.W. Christoffersen et al., even for small-sized hernias the recurrence rate is as high as $14 \%$ in 3 years following the surgery [14]. Shankar et al. reported development of recurrences within 3.1 years after surgery on average in $6 \%$ of patients [10].

To a large extent it also depends on the method of surgery. In our study there were no recurrences after IPOM hernioplasty; hernia recurrence was most commonly encountered after open suture autografting (Mayo technique) - 16\%, after open and hybrid autografting $-8 \%$ and $9 \%$ respectively. Similar results were obtained by other authors: the recurrence rate after using suture techniqus amounted to $9.8 \%$, after using mesh herniopasty - to $2.4 \%$ [10]. In a randomized, double-blind, controlled, multicenter study R. Kaufmann et al. found that within 30 months following the operation the recurrence rate after mesh hernia repair of umbilical hernias from 1 to $4 \mathrm{~cm}$ in size amounted to $4 \%$, after suture hernia repair - to $12 \%$. The most common complications were seromas, hematomas, and wound infections (1-2\%) [15].

In addition to specificity of the surgical intervention, the incidence of complications and recurrences depended on other factors. In particular, a tendency to increase in their number when dealing with hernias larger than $2 \mathrm{~cm}$ in size was detected in overweight patients and in the presence of diabetes mellitus. With this, it can be claimed with a high degree of certainty that the incidence of recurrences really increased. These factors are considered to be the hernia recurrence risk factors, including simultaneous laparoscopic inguinal hernioplasty, smoking, open suture hernia repair of hernias over $1.5 \mathrm{~cm}$ in size and inflammation in the wound area, ascites and liver diseases [10].

The results of our research demonstrate that additional simultaneous surgery does not add to the risk of complications and recurrences. However, in order to improve the results of umbilical hernia surgery, in each particular case it is necessary to carefully select the best method of hernioplasty. First of all, it should be noted that due to the high incidence of complications and recurrences the conventional open suturing technique with tissue materials is not the best choice. Although some authors believe that the choice between alloplasty and autografting is often based on the size of hernia: if the size of hernia gate is less than $2.0 \mathrm{~cm}$ (and in the opinion of Z.Tao et al. [16] less than 2.3 $\mathrm{cm}$ ), autografting can be a possible choice, and if said size is larger, mesh graft alloplasty should be used. But we believe that in addition to this factor it is necessary to take into consideration the thickening of the abdominal wall, which is observed in obese patients. In such cases we recommend to use alloplasty for repair of even small-sized umbilical hernias. We applied this method mainly in the beginning of the reporting period, predominantly for treatment of small hernias. However, even when treating small hernias $(<2.0 \mathrm{~cm}$ in size $)$ in overweight patients this method can cause complications and lead to recurrences.

Due to proper planning of simultaneous operations in our study, they were conducted using the laparoscopic method, which enables additional intervention without additional trau- 
matizing effect. Also of interest is the hybrid approach, which involves elements of open umbilical hernia repair and has the advantages of laparoscopic imaging. This approach has been used by many researchers. Thus, F.P. Prete et al. used laparoscopic imaging during open umbilical hernia repair to monitor placement of mesh endoprosthesis on the peritoneum and to re-position it in $14.3 \%$ of the cases [17]. J.M. Shao et al. also used a hybrid approach - open laparoscopic technique - and additionally performed transabdominal inguinal hernia repair in $58 \%$ of the patients [12]. We believe that in patients who are to undergo simultaneous surgery in the upper abdominal cavity (in particular, for cholecystolithiasis and/or hiatal hernia), in the presence of a small hernia (less than $2 \mathrm{~cm}$ in size) it is highly recommended to use hybrid method of umbilical hernia repair - open access through an incision for a trocar used for laparoscopic cholecystostomy with mesh hernia repair and laparoscopic imaging. For medium $(2-4 \mathrm{~cm})$ and large (over 6 $\mathrm{cm}$ ) hernias and in the presence of obesity and multiple hernias, regardless of the size of the hernia gate, the best choice is IPOM hernia repair using a mesh with anti-adhesive coating, larger than the size of the hernia gate by $5 \mathrm{~cm}$ or more.

\section{CONCLUSIONS}

Summarizing the data obtained, it can be concluded that application of modern endovideoscopic techniques in surgery makes simultaneous surgical interventions not only possible but also necessary in the presence of concomitant abdominal pathology that requires surgical treatment.

\section{REFERENCES}

1. Kirienko A.I., Sazhin A.V., Shevcov Ju .N., et al. Faktory riska razvitija gryzh perednej brjushnoj stenki. Risk factors for the development of hernias of the anterior abdominal wall. Jendoskopicheskaja hirurgija. 2017; 4: 40-46 (RU)

2. Sazhin A., Zolotukhin I., Kirienko A. et al. Prevalence and risk factors for abdominal wall hernia in the general Russian population. Hernia. 2019; 23(3): 1237-1242; doi.org/10.1007/s10029-019-01971-3

3. Bedewi M.A., El-Sharkawy M.S., Al Boukai A.A., Al-Nakshabandi N. Prevalence of adult paraumbilical hernia. Assessment by highresolution sonography: a hospital-based study. Hernia 2012; 16:59-62. DOl: 10.1007/s10029-011-0863-4

4. Dabbas N., Adams K., Pearson K., Royle G.T. Frequency of abdominal wall hernias: is classical teaching out of date? JRSM Short Rep. 2011 Jan; 2(1): 5. doi: 10.1258/shorts.2010.010071

5. Henriksen N.A., Montgomery A., Kaufmann R., et al. European and Americas Hernia Societies (EHS and AHS).Guidelines for treatment of umbilical and epigastric hernias from the European Hernia Society and Americas Hernia Society. BJS. 2020; 107(3): 171-190. Available on: https://bjssjournals.onlinelibrary.wiley.com/doi/full/10.1002/ bjs. 11489

6. Ergul Z., Ersoy E., Kulacoglu H., et al. A simple modified technique for repair of umbilicalhernia in patients undergo laparoscopic cholecystectomy. Report of 10 cases. G Chir. 2009 0ct;30(10):437-9

7. Kamer E, Unalp HR, Derici H, Tansug T, Onal MA. Laparoscopic cholecystectomy accompanied by simultaneous umbilicalhernia repair: a retrospective study. J Postgrad Med. 2007 Jul-Sep;53(3):176-80. doi: $10.4103 / 0022-3859.33859$
8. Vettoretto N., Bartoli M., Montori G., Giovanetti M. Combined laparoscopic cholecystectomy and incisional hernia repair: a proposal for standardised technique. Ann R CollSurg Engl. 2012 Nov;94(8):606. doi: 10.1308/003588412x13373405387096i

9. Yamanaka T., Miyazaki T., Kumakura Y., et al. Umbilical hernia with cholelithiasis and hiatal hernia: a clinical entity similar to Saint's triad. Surg Case Rep. 2015 Dec; 1: 65. doi: 10.1186/s40792-015-0067-8

10. Shankar D.A., Itani K.M.F., O'Brien W.J., Sanchez V.M. Factors Associated With Long-term Outcomes of Umbilical Hernia Repair.JAMA Surg. 2017 May; 152(5): 461-466. doi: 10.1001/jamasurg.2016.5052

11. Christoffersen M.W., Westen M., Rosenberg J., et al. Closure of the fascial defect during laparoscopic umbilical hernia repair: a randomized clinical trial. Br J Surg. 2020 Feb;107(3):200-208.ndoi: 10.1002/bjs.11490

12. Shao J.M., Elhage S.A., Prasad T., et al. Outcomes of LaparoscopicAssisted, Open Umbilical Hernia Repair. Am Surg. 2020 Aug;86(8):10011004. doi: $10.1177 / 0003134820942162$

13. Donovan K., Denham M., Kuchta K. et al. Predictors for recurrence after open umbilical hernia repair in 979 patients. Surgery. 2019 0ct;166(4):615-622. doi: 10.1016/j.surg.2019.04.040

14. Christoffersen M.W., Helgstrand F., Rosenberg J. et al. Long-term recurrence and chronic pain after repair for small umbilical or epigastric hernias: a regional cohort study. Am J Surg 2015; 209: 725-732

15. Kaufmann R., Halm J.A., Eker H.H., et al. Mesh versus suture repair of umbilical hernia in adults: a randomised, double-blind, controlled, multicentre trial. Lancet. 2018 Mar 3;391(10123):860-869.doi: 10.1016/ S0140-6736(18)30298-8

16. Tao Z., Ordonez J., Huerta S. Hernia Size and Mesh Placement in Primary Umbilical Hernia Repair. Am Surg. 2020 Dec 9;3134820971624. doi: 10.1177/0003134820971624

17. Prete F.P., Gurrado A., Pasculli A., et al. A Combined Open and Laparoscopic Technique for the Treatment of Umbilical Hernia: Retrospective Review of a Consecutive Series of Patients. Surg Technol Int. 2020 May 28;36:124-130

\section{ORCID and contributorship:}

Valeriy V. Boiko - 0000-0003-3323-1166 ${ }^{A, F}$

Kyrylo Yu. Parkhomenko - 0000-0002-0004-2417 ${ }^{\text {B,D,F }}$

Kostyantyn L. Gaft - 0000-0002-0288-6488 D,E

Oleksandr E. Feskov - 0000-0003-2601-8252 ${ }^{C, D}$

\section{Conflict of interest:}

The Authors declare no conflict of interest.

\section{CORRESPONDING AUTHOR Kyrylo Yu. Parkhomenko \\ Kharkiv National Medical University \\ 4 Nauky Avenue, Kharkiv, 61022, Ukraine \\ tel: +380501699763 \\ e-mail:patholognew@ukr.net}

Received: 11.09 .2020

Accepted: 08.01.2021

A - Work concept and design, B - Data collection and analysis, C - Responsibility for statistical analysis,

D-Writing the article, $\mathbf{E}$-Critical review, $\mathbf{F}$ - Final approval of the article 